
This ruport was prepared by E. 1. Uu Pont de Nemours and Company (Du Pont) for the United States Department of Energy under Contract DE-ACO9-76SR00001 and is an wecount of work performed under that Contrect. Neither the United Stetes, the United States Department af Energy nor Du Pont, nor any of thair employees, makes any warranty, express or implied, or aseumes any legal liability or responsibllity for the accuracy, completeness, or uafuines of any informetion, apporatus, product, or process discloced herein, or represents that its use will not infringe privetwly owned rights. Reference horoin to any specifle commarical product, procisu, or envles by trade name, mark, menufecturer, or otharwise does not necusearity constitute or imply endorsement, recommendation, or fevoring of ame by Du Pont or by the United States Government or env egency thereof. The viows and opinions of authors expressed herein do not necessarily state or reflect those the Unitud State Government or any agency thereof.

Printed in the United States of Amorica

Avalleble from

Netional Technical information Service

U. S. Dopertmant of Commerce

5285 Port Roval Road

Springfleid, Virginia 22161

Price: Printed Copy A02: Microfiche AO1 
DP-1587

Distribution Category: UC-70

\section{REMOVAL OF SALT FROM HIGH-LEVEL WASTE TANKS BY DENSITY-DRIVEN CIRCULATION OR MECHANICAL AGITATION}

by

D. L. Kiser

Approved by

J. K. Okeson, Research Manager

Engineering Technology Division

Publication Date: January 1981

E. I. du Pont de Nemours \& Co. Savannah River Laboratory Aiken, SC 29808

PREPARED FOR THE U. S. DEPARTMENT OF ENERGY UNDER CONTRACT DE-ACO9.76SR00001 
Twenty-two high-level waste storage tanks at the Savannah River Plant are to be retired in the tank replacement/waste transfer program. The salt-removal portion of this program requires dissolution of about 19 million liters of salt cake. Steam circulation jets were originally proposed to dissolve the salt cake. However, the jets heated the waste tank to 80 to $90^{\circ} \mathrm{C}$. This high temperature required a long cooldown period before transfer of the supernate by jet, and increased the risk of stress-corrosion cracking in these older tanks. A bench-scale investigation at the Savannah River Laboratory developed two alternatives to steam-jet circulation. One technique was density-driven circulation, which in bench tests dissolved salt at the same rate as a simulated steam circulation jet but at a lower temperature. The other technique was mechanical agitation, which dissolved the salt cake faster and required less fresh water than either density-driven circulation or the simulated steam circulation jet. Tests in an actual waste tank verified bench-scale results and demonstrated the superiority of mechanical agitation. 
Introduction ....................... 5

Salt Dissolution by Steam Circulation Jets . . . . . . . 5

Bench-Scale Studies . . . . . . . . . . . . 6

Preparation of Salt Cake . . . . . . . . . . 6

Factors Affecting the Rate of Salt Dissolution . . . 8

Orientation ................ . . 8

Temperature . . . . . . . . . . . . 8

Agitation . . . . . . . . . . . . 8

The Density-Driven Circulation Technique . . . . . 12

The Mechanical-Agitation Techique . . . . . . . 12

Results of Bench-Scale Tests . . . . . . . . . 12

Density-Driven Circulation . . . . . . . . 15

Circulation by Simulated Steam Jet . . . . . . 15

Circulation by Mechanical Agitation . . . . . . 15

Demonstration of Density-Driven

Circulation in a Waste Tank . . . . . . . . . . 17

Demonstration of Circulation by Mechanical Agitation

in a Waste Tank . . . . . . . . . . . . . . 17

Conclusions . . . . . . . . . . . . . . . 21

References ..................... 23 
1 Composition of Synthetic Waste Solution . . . . . . . 7

2 Results of Bench-Scale Salt-Dissolution Tests . . . . 14

\section{LIST OF FIGURES}

Page

1 Measurement of Salt Dissolution on a Horizontal Surface. . . . . . . . . . . . . . 9

2 Measurement of Salt Dissolution on a Vertical Surface................ 10

3 Measurement of Salt Dissolution with Hot Water . . . . 11

4 Flow Pattern of Density-Driven Circulation During Salt Dissolution .. . . . . . . . . . 13

5 Scale Mockups of Three Techniques of Salt Dissolution in a Waste Tank . . . . . . . . . 16

6 Periscopic View of Interior of Waste Tank 10 Before Demonstration of Salt Removal by Density-Driven Circulation . . . . . . . . . . . 18

7 Top View of Waste Tank 10 Showing Arrangement for Demonstration of Salt Removal by Density-Driven Circulation . . . . . . . . . . . . . . . 19

8 Installation of Bingham Pump in Waste Tank 19 for Demonstration of Salt Removal by Mechanical Agitation .. . . . . . . . . . 20

9 Increase of Supernate Specific Gravity with Mechanical Agitation During Bench Test and Fu11-Scale Demonstration in Tank 19... . . . . . . 22 
REMOVAL OF SALT PROM HIGH-LEVEL WASTE TAFK8 DEYSITY-DRIVEN CIRCULATION OR MECHANICAL AGITATION

\section{INTRODUCTION}

Twenty-two high-level waste storage tanks at the Savannah River Plant (SRP) are to be retired. The older tanks consist of three types: Type I, Type II, and Type IV. Type I and Type II tanks have cooling coils and columns, whereas Type IV tanks do not have coils or columns. 1 Nine of the Type I and Type II tanks have leaked through the primary containment to partia! secondary containment. The Type IV tanks, which do not have secondary containment, have no known leaks. These tanks contain about 23 million liters of salt and about 10 million liters of sludge (insoluble solids). These wastes are to be relocated to new Type III, fully stress-relieved tanks that have complete secondary containment. About 19 million liters of salt cake are to be dissolved during salt removal operations.

Steam circulation eductors (jets) were originally proposed for salt dissolution. They are simple to operate (contain no moving parts) and are ideally suited for movement of solutions in a radioactive environment. They have been routinely used in the SRP Waste Tank Farm and separations areas for over two decades.

However, use of steam circulation jets would have several disadvantages because they raise the temperature in the tank. Resultant operational problems include increased risk of tank cracking and long cooldown periods before solution transfer. Therefore, alternative dissolution techniques were investigated by bench-scale tests. These tests showed that the ability of fresh water to contact the cake surface is the most significant factor influencing the rate of salt dissolution. Density-driven circulation and mechanical agitation techniques were developed on the bench scale and demonstrated in an actual waste tank.

\section{SALT DISSOLUTION DY STEAM CIRCULATION JETS}

Previous salt dissolution at SRP was done in Tank 22, The best results from Tank 22 became the basis for the conceptual process for salt removal. Two steam circulation jets per tank were proposed. Initially, the jets were to be mined into the salt cake to a depth of about 2.4 meters. About 340,000 liters of 
water and steam were to be added to each batch, while each - jet circulated the liquid at $284 \mathrm{~L} / \mathrm{min}$ until eight volume turnovers were completed. The objective was to dissolve 113,000 liters of salt cake.

Steam, used to power the jets, added condensate to the supernate and heated the contents of the tank to 80 to $90^{\circ} \mathrm{C}$. Consequently, a cooldown period was required before the supernate could be removed from the tank with a transfer jet. A steam jet will outgas, depending on the solution temperature and the suction and discharge heads. The projected cooldown periods would be as long as 10 months for Type I tanks (with cooling coils) and 24 months for Type IV tanks (without cooling coils). Tank cooldown would increase the time required for salt removal by a factor of five for Type I tanks and by a factor of ten for Type IV tanks. Elevating the temperature in the old type tanks would greatly increase the risk of nitrate stress-corrosion cracking of the carbon steel liner. ${ }^{2}$ Furthermore, the extra water vapor generated by the higher temperature would require larger ventilation systems on each tank for successful use of steam circulation jets. To alleviate these problems, a bench-scale development program was initiated to evaluate alternative techniques.

\section{BETCH-SCALE STUDIES}

\section{Preparation of Salt Cake}

Salt cake was prepared for bench-scale studies by mixing chemicals in a beaker to form a concentrated synthetic liquid waste whose composition (Table 1) was close to the average composition of concentrated supernate from the Waste Tank Farm. A 44\% sodium hydroxide solution was heated to $90^{\circ} \mathrm{C}$ with stirring. Sodium nitrite, sodium chloride, sodium sufate, and sodium carbonate were added slowly in that order. The solution was allowed to cool to 80 to $85^{\circ} \mathrm{C}$. A $60 \%$ aluminum nitrate solution was then pumped slowly into the beaker to form sodium aluminate and sodium nitrate. The temperature was lowered below $100^{\circ} \mathrm{C}$ to avoid decomposition of aluminum nitrate; above $100^{\circ} \mathrm{C}$, nitrate decomposition generated a brown vapor $\left(\mathrm{NO}_{2}\right)$.

Upon completion of the chemical additions, the solution was heated to the boiling point $\left(122^{\circ} \mathrm{C}\right)$, and boiling was continued until $20 \%$ of the original volume had evaporated. The solution was then placed in a insulated beaker or jar and cooled slowly to room temperature. The concentrated supernate was decanted and reboiled (boiling point usually $130^{\circ} \mathrm{C}$ ) until $20 \%$ of the original volume was evaporated. A third boildown (usually at $139^{\circ} \mathrm{C}$ ) removed most of the remaining salt. 


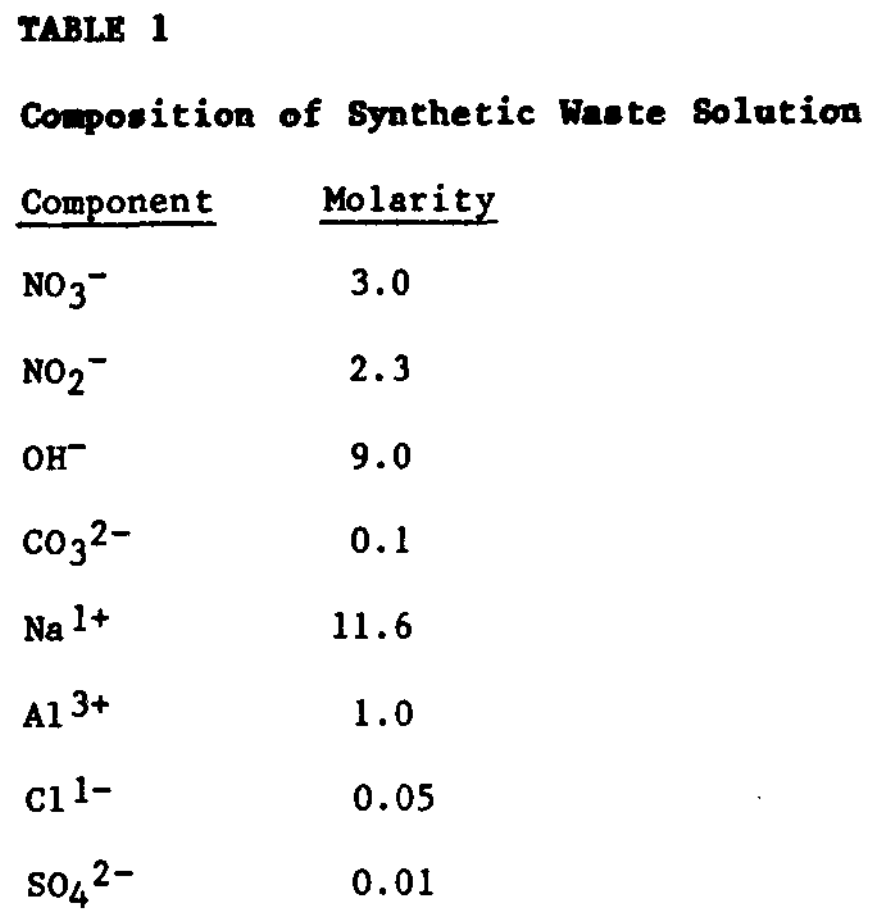




\section{Factors Affecting the Rate of Salt Dissolution}

Previous bench-scale tests had achieved salt dissolution rates in the range of 3.05 to $182.88 \mathrm{~cm} / \mathrm{hr}$ with the salt cake block immersed to expose the bottom surface to the dissolving water. ${ }^{3}$ The dissolution rate is the volume of cake dissolved per cake surface area per unit time.

Orientation. A review of the Tank 22 salt-dissolution data showed that the dissolution rate was much higher for cake in a vertical plane (about $3.65 \mathrm{~cm} / \mathrm{hr}$ for cake on the tank wall) than for cake in a horizontal plane $(0.06 \mathrm{~cm} / \mathrm{hr})$. A bench-scale experiment was conducted in a four-1iter beaker $(14.9-\mathrm{cm}$ diameter) to determine separate dissolution rates for horizontal and vertical salt surfaces. Figures 1 and 2 show diagrams of the experimental apparatus. In Figure 1, salt was crystalized in the bottom of the beaker. Tap water was added as a batch for dissolution in the horizontal plane. Supernate was continuously pumped from the beaker until dry. Then another batch of water was added, and the cycle was repeated. In Figure 2, an annular ring of salt was formed on the beaker wall. Tap water was added as a batch iust filling the center of the salt annulus. Water was then continuously added and supernate continuously removed from the bottom of the annulus as the salt cake dissolved. The vertical-plane dissolution rate was $3.05 \mathrm{~cm} / \mathrm{hr}$; the horizontal-plane dissolution rate was $0.06 \mathrm{~cm} / \mathrm{hr}$.

Temperature. Because the solubilities of sodium nitrate and sodium nitrite increase with increasing temperature, a dissolution experiment was performed in the four-1iter beaker with hot tap water (inlet temperature 65 to $70^{\circ} \mathrm{C}$, average supernate temperature in beaker $40^{\circ} \mathrm{C}$ ). A vertical hole was bored in the salt cake for supernate removal (Figure 3 ). Water was continuously added and supernate was continuously removed. The dissolution rate at $40^{\circ} \mathrm{C}$ was $0.12 \mathrm{~cm} / \mathrm{hr}$ faster than for an experiment at $20^{\circ} \mathrm{C}$. The $17 \%$ increase in dissolution rate for the $20^{\circ} \mathrm{C}$ temperature increase corresponded to a similar solubility increase for nitrate or nitrite over the same temperature change. Water vapor losses from the glass vessel at $40^{\circ} \mathrm{C}$ were large enough to preclude meaningful salt-dissolution experiments at higher temperatures with an open system.

Agitation. The last factor investigated was agitation of the dissolution liquid. Tap water was added as a batch to the four-liter beaker with salt cake in the bottom, as shown in Figure 1. A laboratory stirrer (a two-blade propeller, $5.1 \mathrm{~cm}$ in diameter) was placed in the center of the beaker just above the salt cake surface. The supernate was monitored for specific gravity, and agitation was terminated at a specific gravity of 1.3. The dissolution rate ranged from $1.22 \mathrm{~cm} / \mathrm{hr}$ at a stirrer speed of $425 \mathrm{rpm}$ to $1.74 \mathrm{~cm} / \mathrm{hr}$ at $1200 \mathrm{rpm}$. At $1200 \mathrm{rpm}$, vortexing and 


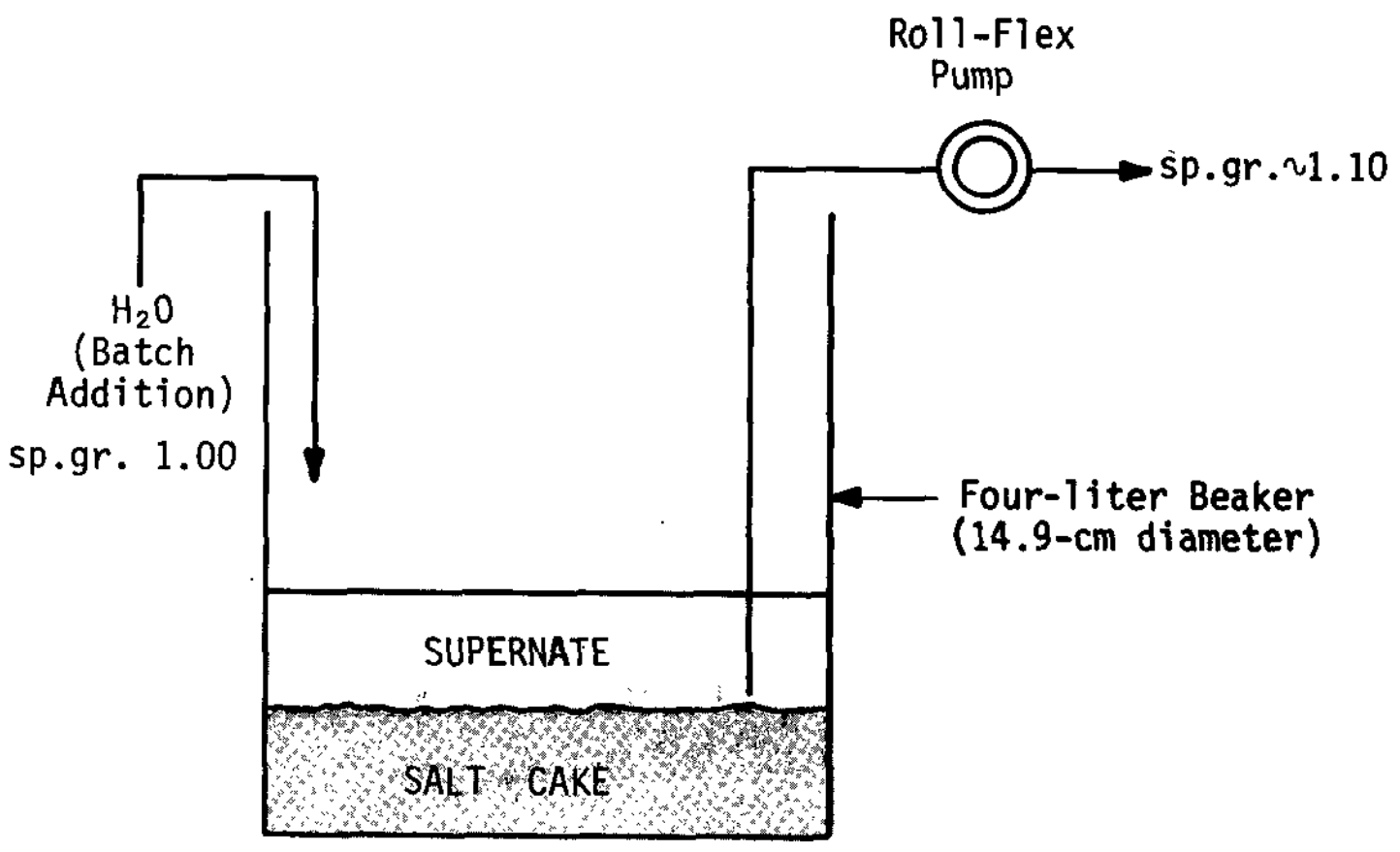

FIGURE 1. Measurement of Salt Dissolution on a Horizontal Surface 


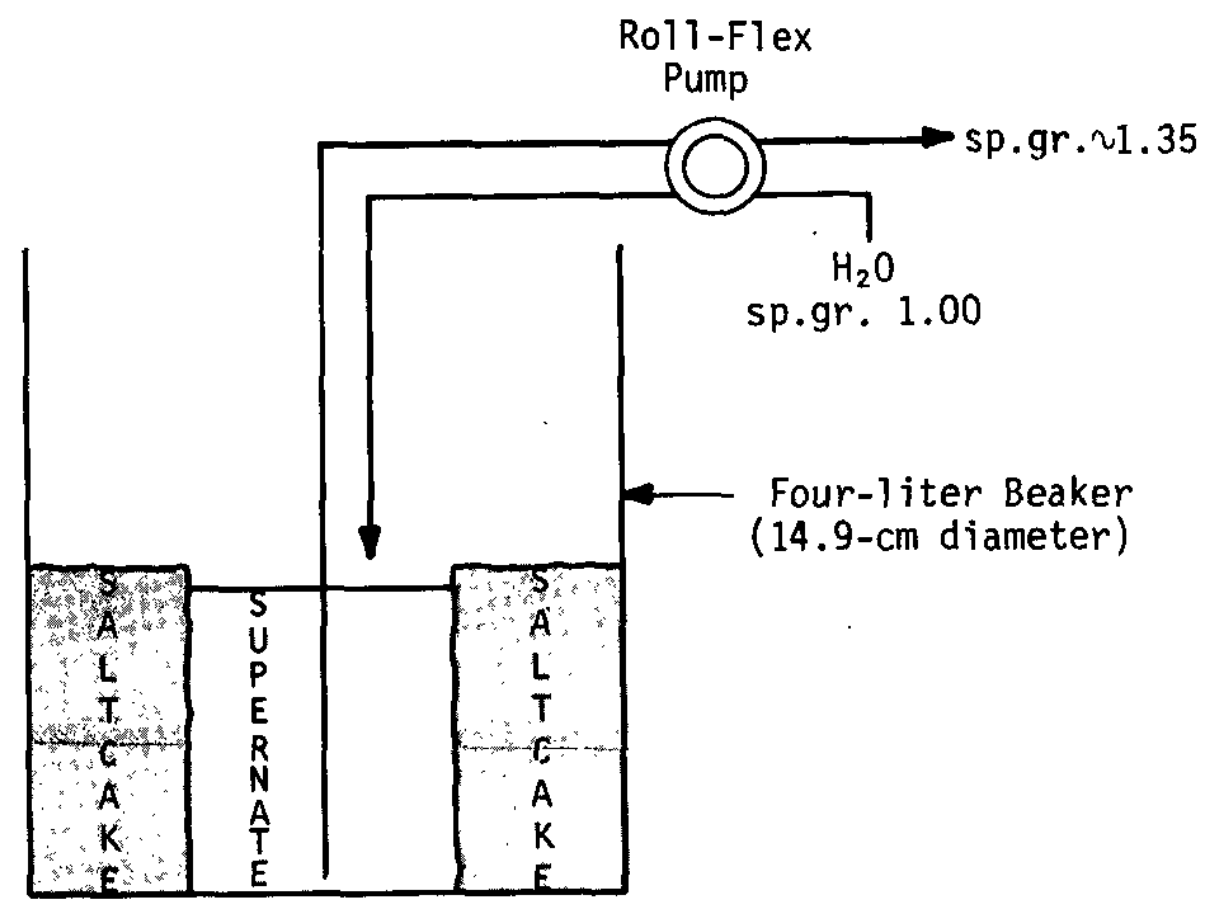

FIGURE 2. Measurement of Salt Dissolution on a Vertical Surface 


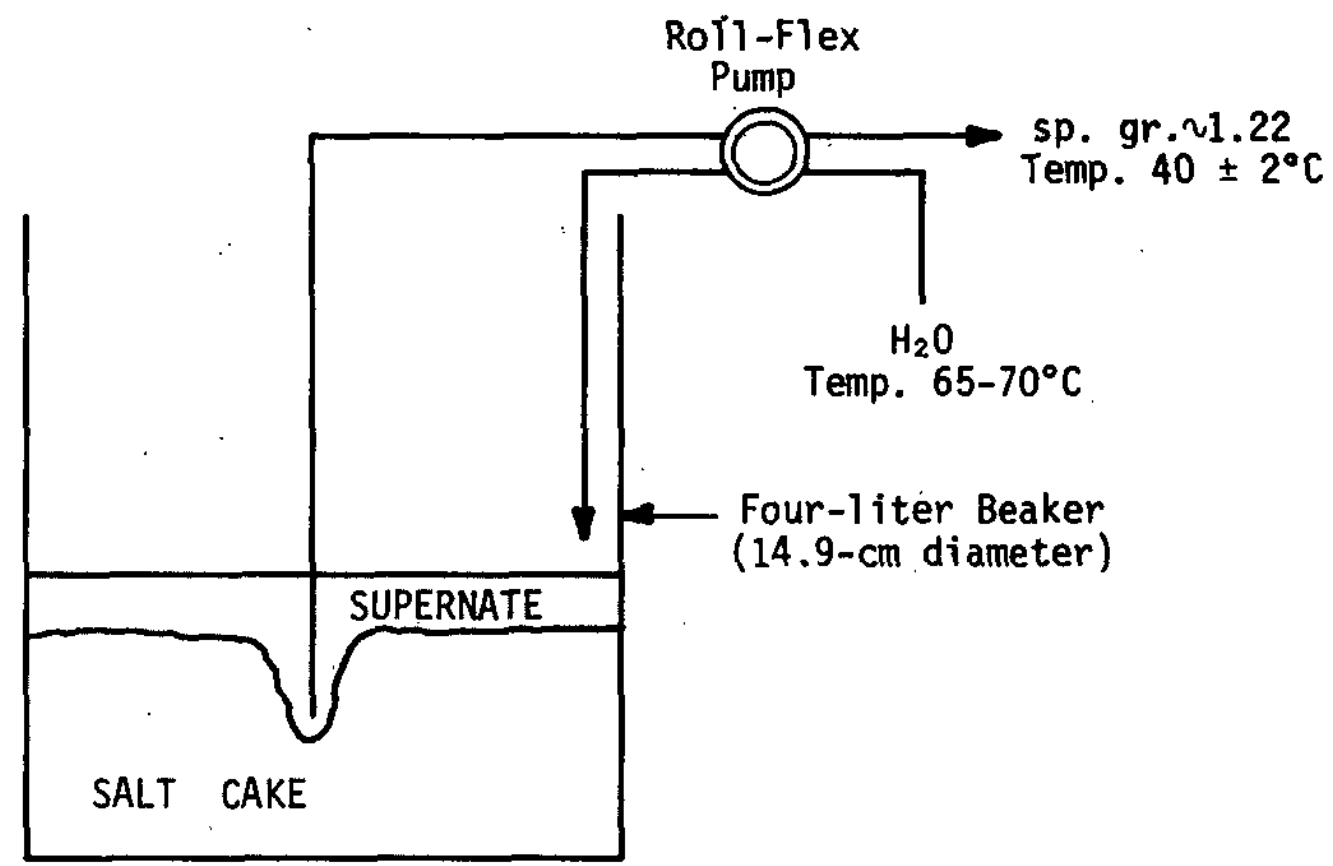

FIGURE 3. Measurement of Salt Dissolution with Hot Water 
some splashing occurred. When the supernate was removed, a crater with ledges was visible under the stirrer.

\section{The Density-Driven Circulation Technique}

A vertical well was mined into salt cake deposited in the bottom of a four-liter beaker. Water at ambient temperature was added continuously to the beaker to dissolve the upper layer of salt cake. The resulting supernate flowed into the well by gravity because of its higher density (about $1.3 \mathrm{~g} / \mathrm{cm}^{3}$ ). Figure 4 shows the flow pattern. This denser material could be removed by pumping or jetting from the bottom of the well.

In Tank 22, a mined wel1 was a significant factor in reaching an acceptable dissolution rate for salt cake not on the tank wall. A steam circulation jet dissolved salt cake in Tank 22 at a rate of $0.14 \mathrm{~cm} / \mathrm{hr}$ without a mined well, compared to $0.38 \mathrm{~cm} / \mathrm{hr}$ with a mined well.

The density-driven technique uses simple equipment and eliminates problems associated with elevated temperatures in a salt tank. However, this technique has two disadvantages. As the well becomes shallow, approaching a cake heel in the tank, the dissolution rate diminishes to the rate in the horizontal plane. And if sludge is dispersed to any significant extent (probably several percent) in the salt cake, the sludge will settle out as the salt dissolves and blanket the cake surface, reducing the dissolution rate.

\section{The Mechanical-Agitation Technique}

Agitation of the liquid above the salt surface by mechanical agitators or centrifugal pumps would overcome the disadvantages of the density-driven technique. Such agitation would suspend the sludge and would minimize salt concentration gradients, thereby eliminating dissolution inhibition at the cake surface-liquid interface. Agitation should be sufficient to accomplish this objective, but it should not be so vigorous as to erode salt from the cake. Salt cake erosion increases the risk of undercutting the cake surface. Undercutting occurs in a heterogeneous cake because of the presence of salts with different solubilities.

\section{Resulta of Bench-Scale Tests}

Bench-scale tests showed that density-driven circulation dissolved a salt cake almost as fast as simulated steam-jet circulation but significantly less rapidly than circulation by mechanical agitation (Table 2). 


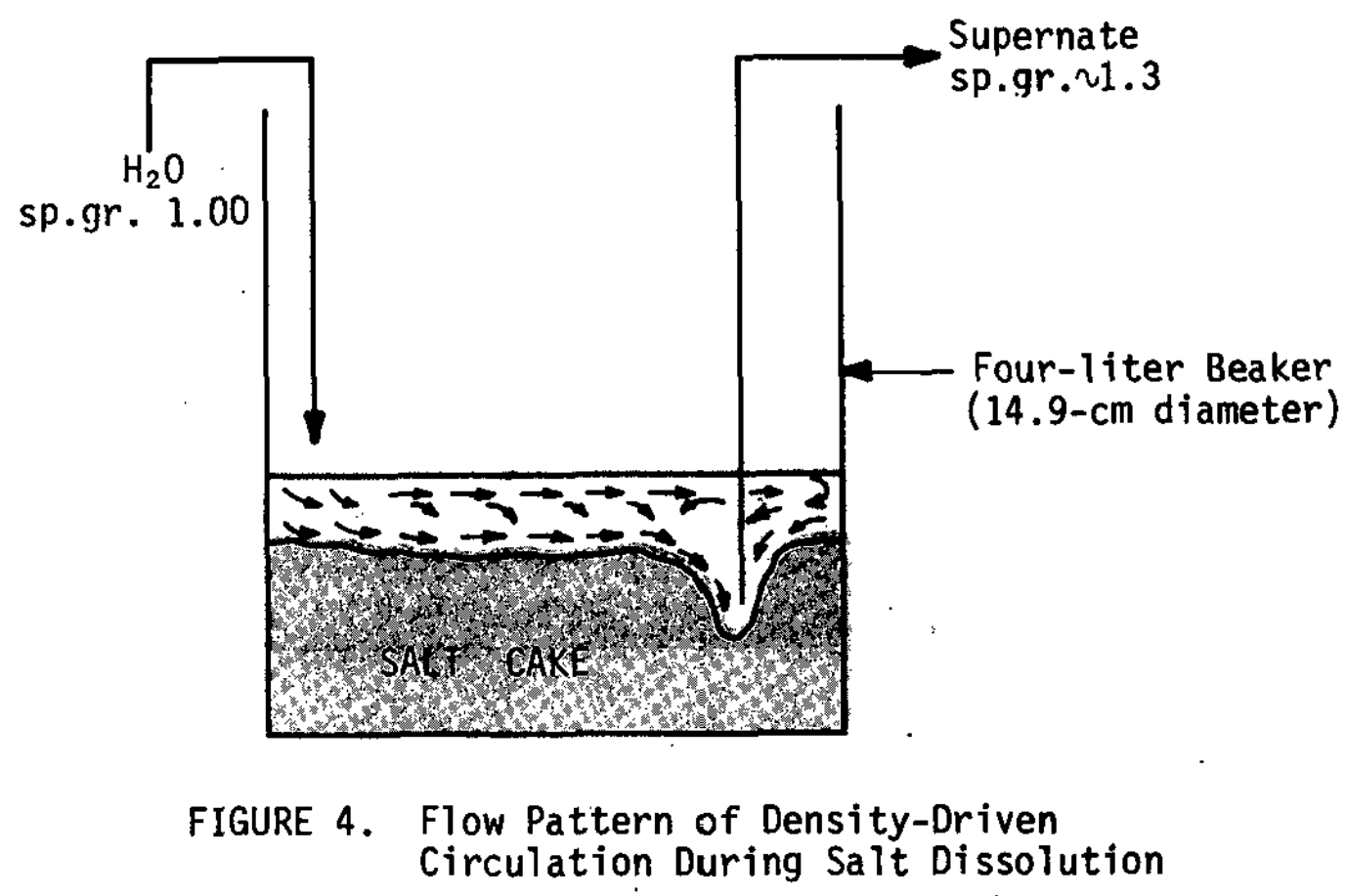




\section{TABLE 2}

\section{Reeults of Dench-Scale Salt-Disuolution Tests}

\begin{tabular}{|c|c|c|c|c|}
\hline $\begin{array}{l}\text { Circulation } \\
\text { Technique }\end{array}$ & $\begin{array}{l}\text { Cake } \\
\text { Dissolution } \\
\text { Rate, cm/hr }\end{array}$ & $\begin{array}{l}\text { Specific Gravity } \\
\text { of Supernate } \\
\text { when Removed* }\end{array}$ & $\begin{array}{l}\text { Rate of } \\
\text { Supernate } \\
\text { Removal, } \\
\text { mL/min } \\
\end{array}$ & $\begin{array}{l}\text { Ratio of } \\
\text { Water Added } \\
\text { to Salt Cake } \\
\text { Dissolved, } \mathrm{g} / \mathrm{g}\end{array}$ \\
\hline Density Driven & 0.31 & 1.30 & $11 * *$ & 1.1 \\
\hline Steam Jet & 0.33 & 1.30 & $t$ & 1.2 \\
\hline $\begin{array}{l}\text { Mechanical } \\
\text { Agitation }\end{array}$ & 1.28 & 1.30 & $t+$ & 1.1 \\
\hline $\begin{array}{l}\text { Mechanical } \\
\text { Agitation }\end{array}$ & 0.58 & 1.40 & $\dagger t$ & 0.6 \\
\hline
\end{tabular}

$\star \pm 0.01$

** Continuous.

$\uparrow$ Recirculated at $35 \mathrm{~mL} / \mathrm{min}$, pumped at termination as a batch.

t† Pumped as a batch at termination only. 
Density-Driven Circulation. For this test, salt cake was formed in $30.5-\mathrm{cm}$-diameter jar to a height of $7.6 \mathrm{~cm}$ (Figure 5). The diameter-to-height ratio of $4: 1$ simulated the ratio in an actual waste tank. A roll-flex tubing pump removed or circulated the liquid. To form the well, a hole was jetted into the salt cake with tap water from a $0.3-\mathrm{cm}$ stainless steel tube attached to the plastic tubing from the pump. The removal rate $(11 \mathrm{~mL} / \mathrm{min})$ scales to a density-driven removal rate of 79 liters/min in a 25.9-meterdiameter waste tank, based on the ratio of the squares of the vessel diameters. The removal rate is a function of the cake surface area (approximated by the vessel cross-sectional area) for a constant dissolution rate.

Circulation by simulated steam Jet. To test the steam-jet circulation technique, the same apparatus was used, but the pump discharge from the withdrawal point was proportioned relative to a full-scale steam circulation jet. The $35-\mathrm{mL} / \mathrm{min}$ recirculation rate was scaled from 248 liters/min for a full-scale jet, based on the difference in liquid volume of the vessels; the circulation rate depends on the circulation area, which is determined by the liquid volume of the vessel. For comparison of dissolution rates, the supernate was removed from the jar when its specific gravity reached 1.3. This was the highest specific gravity attained during dissolution of horizontal planar salt surfaces in Tank 22. Test results show that jet circulation does not significantly improve the flow pattern of the density-driven technique. A dissolution rate of $0.45 \mathrm{~cm} / \mathrm{hr}$ would be expected for simulated steam-jet circulation if the rate were adjusted for the higher temperatures typical of operation with steam jets. The rate was extrapolated to the temperature expected during operation with steam jets, based on the experimental evaluation of the temperature effect.

Circulation by Mechanical Agitation. Three laboratory stirrers were placed in the $30.5-\mathrm{cm}$-diameter jar in a triangular pattern at positions scaled to simulate risers in Type IV tanks (Figure 5). The two-blade impellers were positioned 0.6 to $1.3 \mathrm{~cm}$ above the initial surface of the salt cake. The blade diameter was $2.5 \mathrm{~cm}$. Agitation was terminated when the specific gravity of the supernate attained either 1.3 or 1.4 . At a supernate specific gravity of 1.3 , the dissolution rate by mechanical agitation was about four times faster than dissolution by density-driven circulation. At a specific gravity of 1.4 , the dissolution rate by mechanical agitation was twice the rate by density-driven circulation. In addition, mechanical agitation with drawoff at a specific gravity of 1.4 required only about half as much water as densitydriven circulation with drawoff at a specific gravity of 1.3 . 
DENSITY-DRIVEN CIRCULATION:

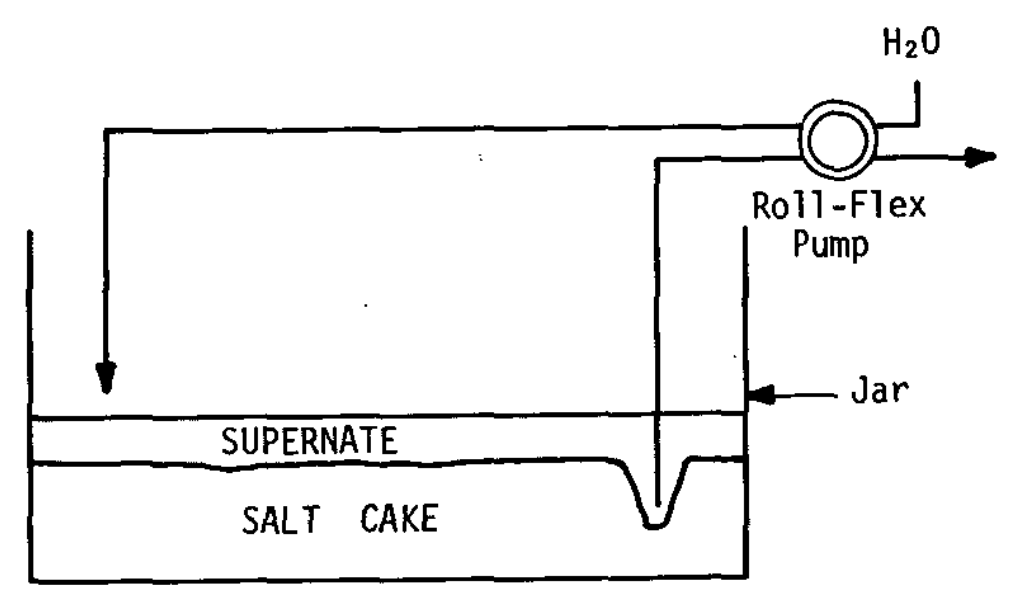

๘ே
Jar Diameter $=30.5 \mathrm{~cm} \quad 1 / 85$ of Dimensions in Waste Tank Salt Cake Height $=7.6 \mathrm{~cm}$ Jar Diameter/Salt Cake Height $=4$, as in Waste Tank
SIMULATED STEAM-JET CIRCULATION:

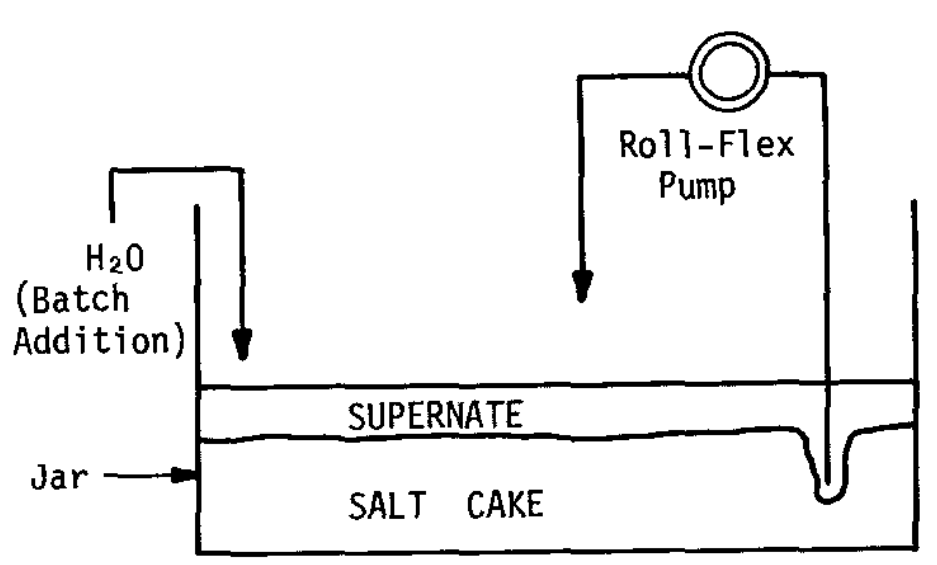

MECHANICAL AGITATION:

Three Stirrers

Stirrer Speed: $1000 \pm 100 \mathrm{rpm}$

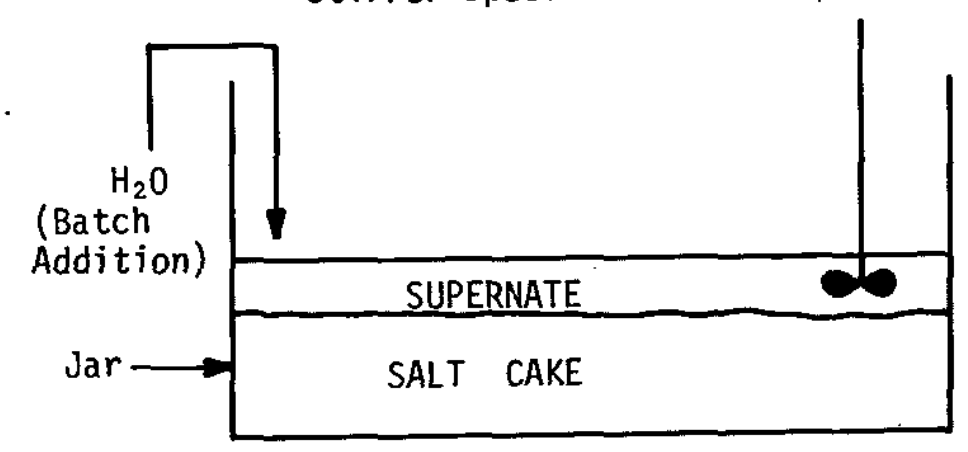

FIGURE 5. Scale Mockups of Three Techniques of Salt Dissolution in a Waste Tank 


\section{DEMONSTRATION OF DENSITY-DRIVEN CIRCULATION IN A WASTE TANR}

Tank 10, a 22.9-meter-diameter Type I tank with cooling coils and columns, 1 was selected for the plant demonstration (Figure 6 ). An FF-3 stearn jet was selected for the transfer-out jet. This jet has a capacity of about 76 liters/min, close to the scaled removal rate used for the bench-scale investigation. Using an attached water-spray ring, the jet was mined into the salt cake to about 2.4 meters from the bottom of the tank. Figure 7 shows the tank demonstration set-up. The salt cake was about 5.2 meters thick. The cake volume was about 1.9 million liters. Low-level waste water was jetted from Tank 23 to dissolve the salt.

When about $28 \%$ of the salt had been dissolved, the specific gravity of the supernate averaged 1.38 ; the dissolution rate was calculated to be $0.43 \mathrm{~cm} / \mathrm{hr}$. The liquid temperature was 50 to $55^{\circ} \mathrm{C}$, compared to $20^{\circ} \mathrm{C}$ for the bench-scale experiments. Dissolution water was fed continuously at an average rate of 431 iters/min. The dissolved salt supernate and the condensate from the transfer jet were removed at an average rate of 69 liters/min.

When about $50 \%$ of the salt had been dissolved, the specific gravity of the supernate had decreased to about 1.30 and the dissolution rate had diminished from $0.43 \mathrm{~cm} / \mathrm{hr}$ to about $0.30 \mathrm{~cm} / \mathrm{hr}$. The liquid level in the tank was then lowered to expose the remaining cake. Periscopic inspection of the cake surface revealed sludge covering a high mound opposite the location of the transfer jet (Figure 7). The mound occupied about one-third of the cake surface area. Mechanical agitation will therefore be necessary when dissolution by density-driven circulation reaches a point of diminishing returns.

\section{DEMONSTRATION OF CIRCULATION BY MECHANICAL AGITATION IN A VASTE TANR}

Tank 19, a 25.9-meter-diameter Type IV tank without cooling coils or columns, 1 was selected for this plant demonstration. Tank 19 contained about 3.8 million liters of salt cake and about 34,000 liters of spent zeolite resin from a cesium-removal column located in one of the tank risers. A long-shaft centrifugal pump (Bingham Willamette Company) was inserted in a riser and lowered to the level of salt, about 7.7 meters thick (Figure 8 ). The pump was 13.7 meters long ( 9 casing sections) and was made of Type 304 stainless steel. An adjustable-speed drive operated the 150-hp motor coupled to the end of the long shaft. The pump, with a capacity of 4,540 liters/min, was rotated at about $0.2 \mathrm{rpm}$ by a turntable secured to the top of the riser (Figure 8 ). A steam jet. in an adjacent riser was used to transfer liquid from the tank. 


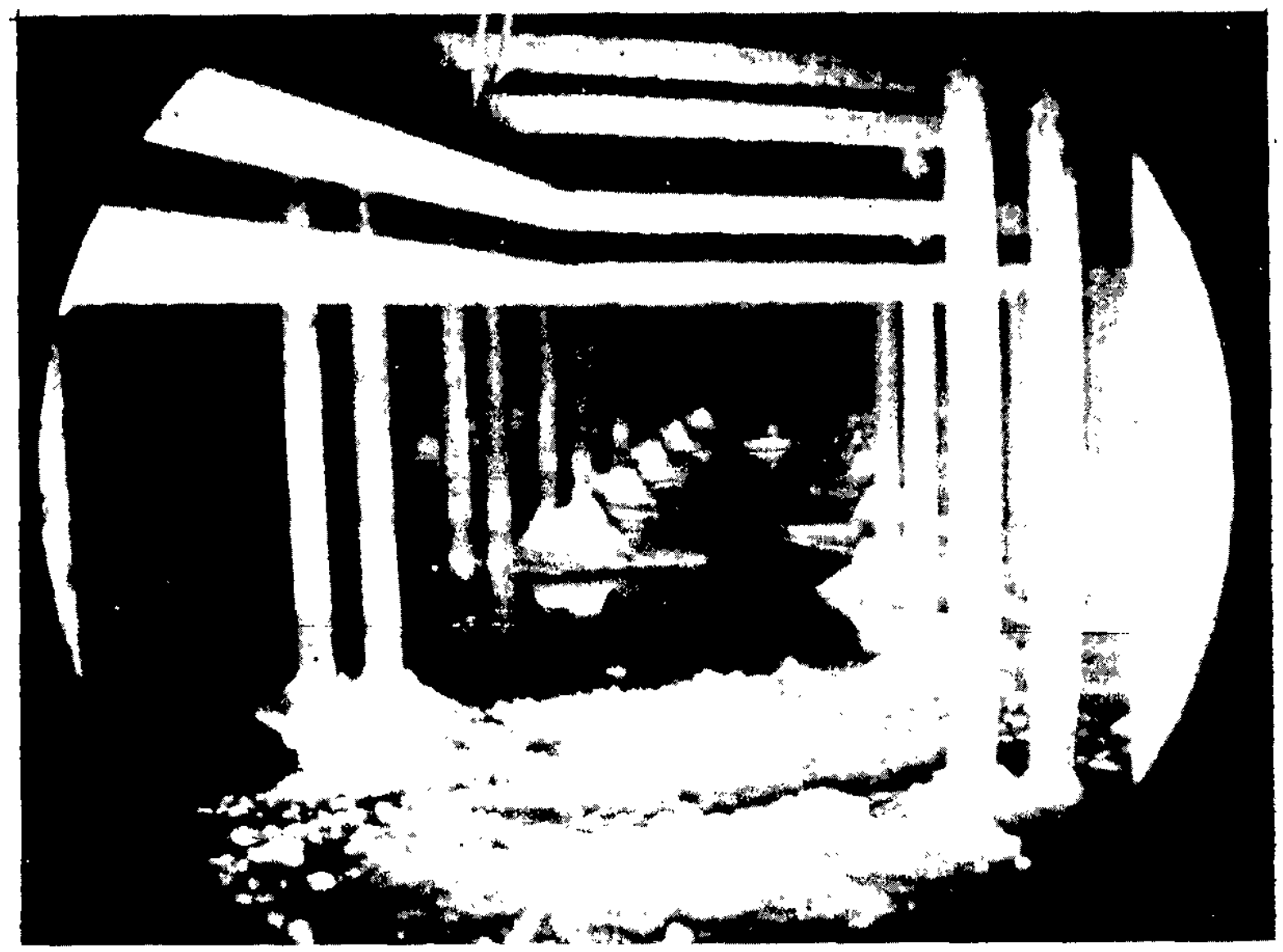

FIGURE 6. Periscoptc View of Interior of Waste Tank 10 Before Demonstration of Salt Removal by Density-Driven Circulation 


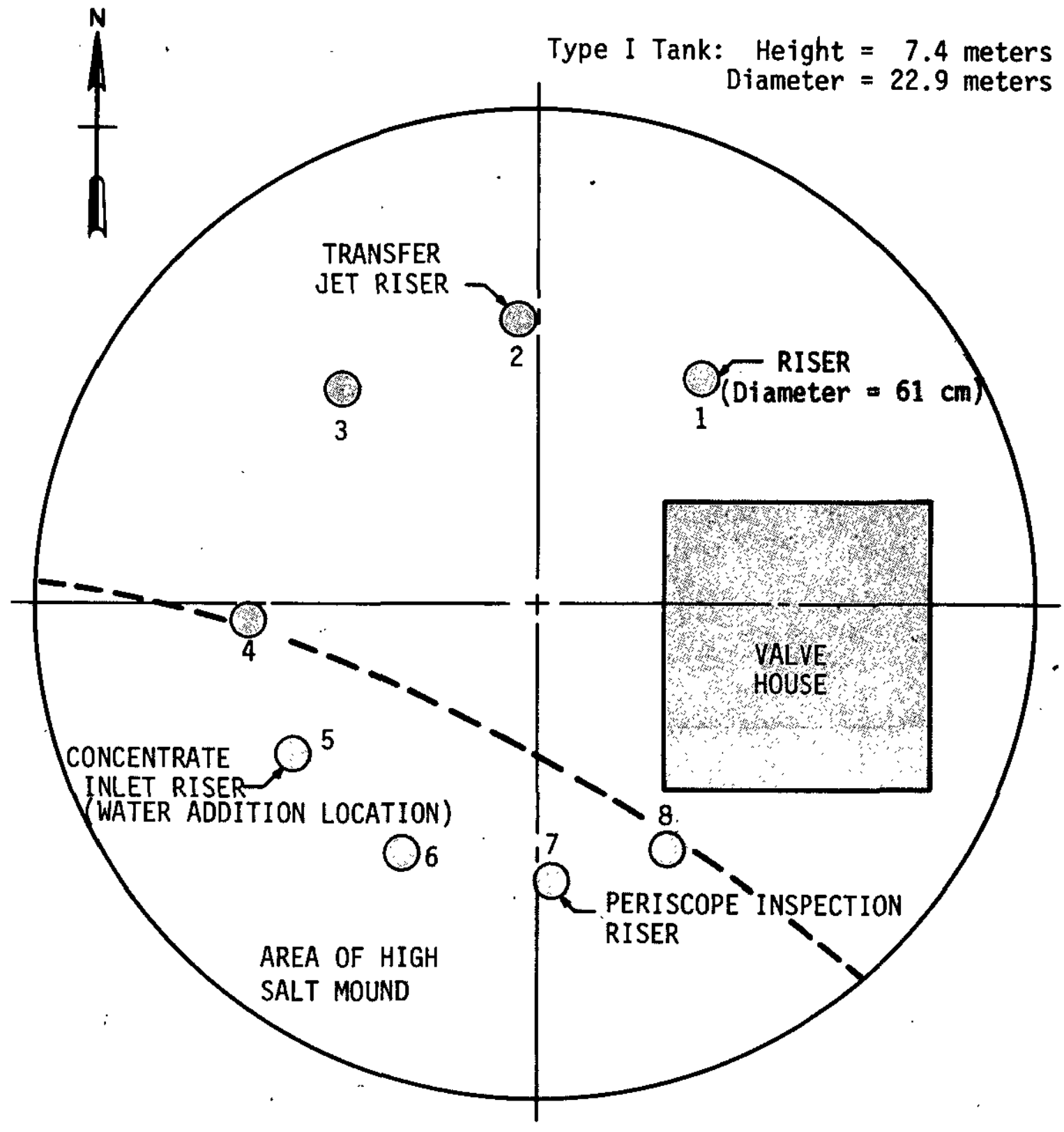

FIGURE 7. Top View of Waste Tank 10 Showing Arrangement for Demonstration of Salt Removal by Density-Driven Circulation 
Type IV Tank:

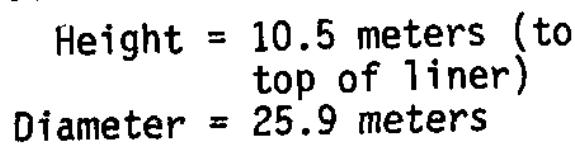

25.9 meters

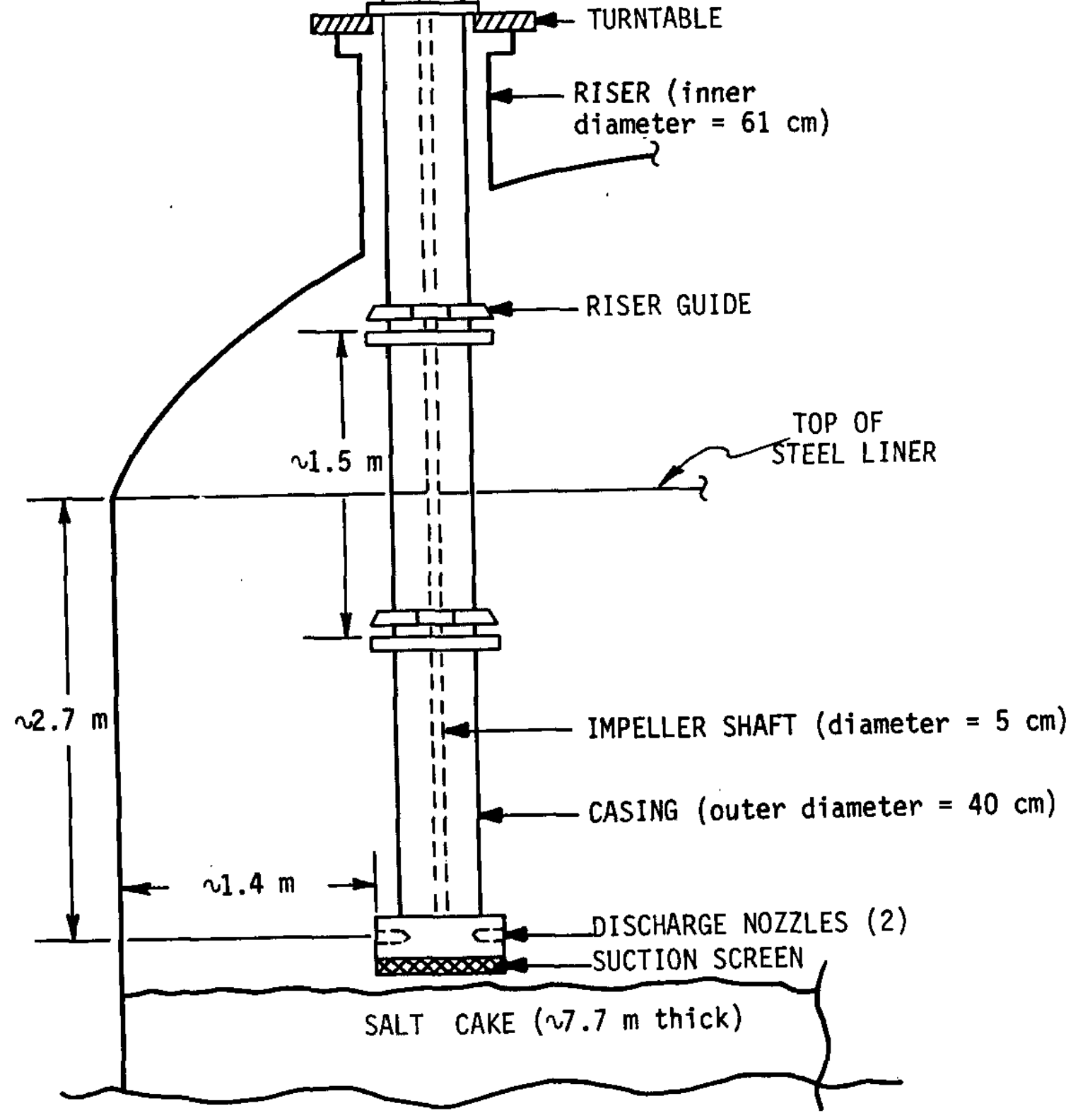

FIGURE 8. Installation of Bingham Pump in Waste Tank 19 for Demonstration of Salt Removal by Mechanical Agitation 
For this batch-dissolution test, 908,000 liters of well water with added sodium hydroxide $(0.55 \mathrm{M})$ to inhibit corrosion was pumped into the tank. The water submerged the pump discharge nozzles in about 1.5 meters of liquid. The pump was started up at the minimum speed of $600 \mathrm{rpm}$ and increased to full speed $(1,760 \mathrm{rpm})$ over a two-hour period. The temperature of the liquid was about $30^{\circ} \mathrm{C}$. After 90 hours of full-speed operation, the salt solution reached a specific gravity of 1.35 . Figure 9 shows that when the scale-up factor is taken into account, the rate of increase of specific gravity during this full-scale demonstration is similar to the rate of increase during the bench-scale experiment. The tank demonstration time was 85 times that of the bench-scale experiment (the ratio of the diameters of the two vessels); events tend to occur

85 times more rapidly in the bench-scale jar than in the full-scale tank.

Dissolution of the salt cake in Tank 19 was terminated at a specific gravity of 1.40 , when an estimated 650,000 iiters of salt had been dissolved.

\section{CONCLUSIONS}

The full-scale waste tank demonstrations were in good agreement with the bench-scale experiments at $1 / 85$ scale.

Density-driven circulation utilizes simple equipment, but leaves a cake heel in the tank and is hindered by the presence of sludge or zeolite in the salt cake.

Mechanical agitation overcomes the problems associated with both steam-jet circulation and density-driven circulation. Mechanical agitation is the best method for future removal of salt from waste tanks. 
Dissolution Time in Tank 19, hours

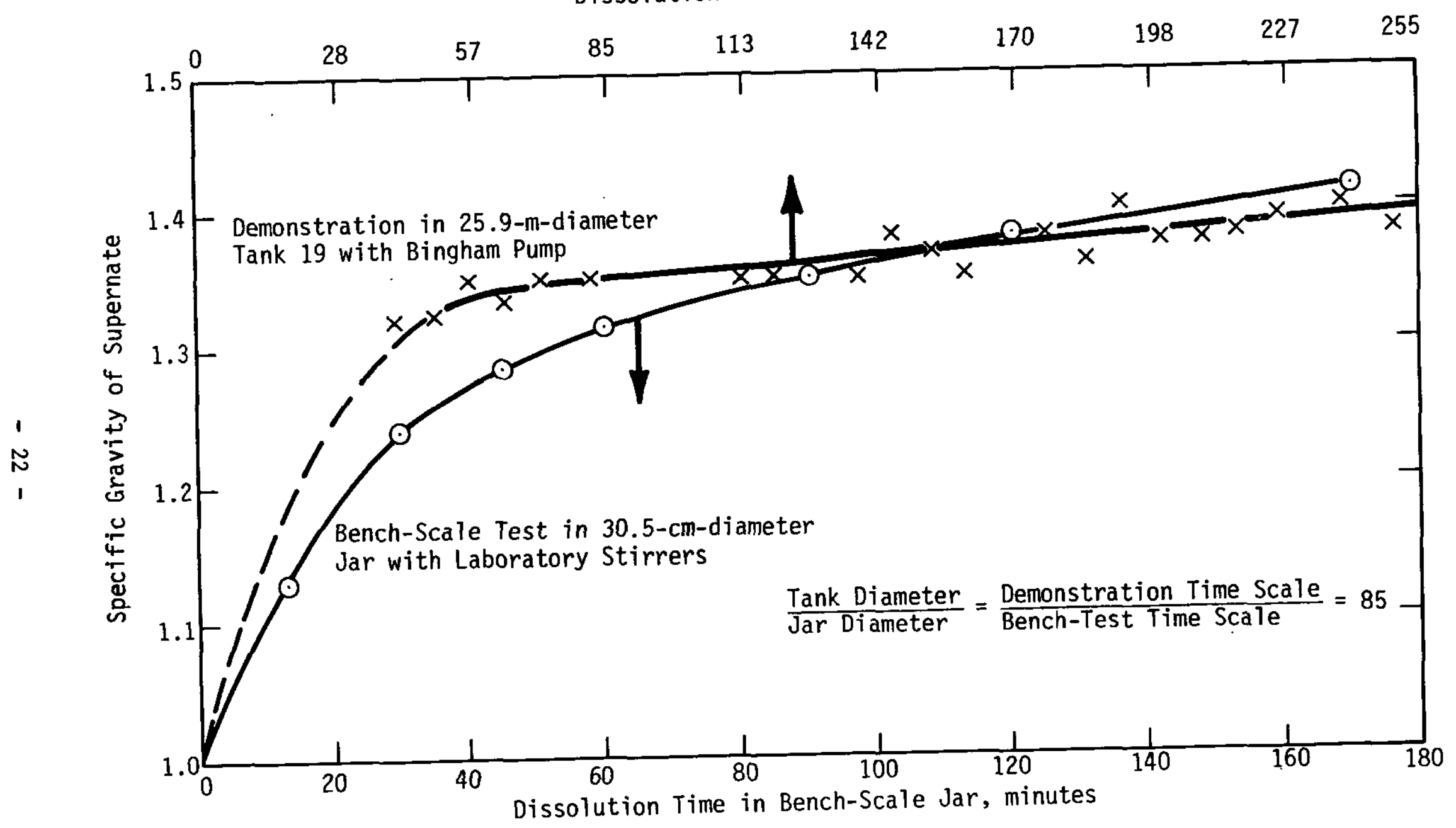

FIGURE 9. Increase of Supernate Specific Gravity with Mechanical Agitation During Bench Test and Full-Scale Demonstration in Tank 19 
1. J. A. Donovan. Material Aspects of SRP Waste storage Corrosion and Mechanical Failure. pp. 10-14, USDOE Report DP-1476, E. I. du Pont de Nemours and Co., Savannah River Laboratory, Aiken, SC (1977).

2. R. S. Ondrejcin. Prediction of Stress Corrosion of Carbon Steel by Nuclear Process Liquid Wastes. USDOE Report DP-1478, E. I. du Pont de Nemours and Co., Savannah River Laboratory, Aiken, SC (1978).

3. C. B. Goodlett. Concentration of Radioactive Wastes. USAEC Report DP-1135, E. I. du Pont de Nemours and Co., Savannah River Laboratory, Aiken, SC (1968). 